\title{
New design of wideband microstrip branch line coupler using T-shape and open stub for 5G application
}

\author{
Ali Abdulateef Abdulbari', Sharul Kamal Abdul Rahim², Mohamad Zoinol Abidin Abd Aziz ${ }^{3}$, \\ K. G. Tan ${ }^{4}$, N. K. Noordin ${ }^{5}$, M. Z. M. Nor ${ }^{6}$ \\ ${ }^{1,2}$ Wireless Communication Centre (WCC), School of Electrical Engineering, Universiti Teknologi Malaysia (UTM), \\ Skudai, Malaysia \\ ${ }^{3}$ Centre for Telecommunication Research and Innovation (CeTRI), Faculty of Electronic and Computer Engineering, \\ Universiti Teknikal Malaysia Melaka (UTeM), Melaka, Malaysia \\ ${ }^{4}$ Faculty of Engineering and Technology, Multimedia University, Melaka, Malaysia \\ ${ }^{5}$ Faculty of Engineering, University Putra Malaysia, Selangor, Malaysia \\ ${ }^{6}$ Faculty of Electrical Engineering, UiTM Cawangan Johor, Kampus Pasir Gudang, Johor, Malaysia
}

\begin{tabular}{l} 
Article Info \\
\hline Article history: \\
Received Apr 2, 2020 \\
Revised Jul 16, 2020 \\
Accepted Sep 26, 2020 \\
\hline Keywords: \\
3-dB branch-line coupler \\
5G \\
Phase shift \\
Slot T shape \\
T- model open stub \\
Wideband BLC
\end{tabular}

Article Info

Article history:

Received Apr 2, 2020

Revised Jul 16, 2020

Keywords:

3 -dB branch-line coupler

Phase shift

T- model open stub

Wideband BLC

\begin{abstract}
A new design of wideband branch-line coupler (BLC) using T-shape with open stub microstrip line is proposed. The branch line coupler is integrated with low and high impedance $\lambda / 4$ transmission lines to achieve the comparatively compact size of $(27.2 \mathrm{~mm} \times 16.5 \mathrm{~mm})$. Operating the bandwidth in simulated of BLC from 2.9 to $4 \mathrm{GHz}$ is obtained $30.22 \%$ with a frequency center of 3.5 GHz. Meanwhile, the measured bandwidth of the BLC is cover from $2.8 \mathrm{GHz}$ to $4.22 \mathrm{GHz}$ is equal $33.40 \%$ at the center frequency $3.55 \mathrm{GHz}$ respectively. The BLC simulated has low isolation and high return loss of $-29.28 \mathrm{~dB}$ and $-30.69 \mathrm{~dB}$ at the center frequency 3.5 GHz. Whereas, the measured result has a simple difference in the return loss and isolation are $27.43 \mathrm{~dB}$ and $-24.46 \mathrm{~dB}$ at the frequency $3.55 \mathrm{GHz}$ respectively. This BLC design has a good coupling factor of -2.97 and insertion loss of $-3.65 \mathrm{~dB}$. Furthermore, it obtains an excellent amplitude and phases different between two output of \pm 0.1 and $93.6^{\circ} \pm 3.4^{\circ}$ with high performance. There is a good agreement between the simulated result and the measured result. This branch line coupler design used for $5 \mathrm{G}$ applications for future wireless communication systems.
\end{abstract}

This is an open access article under the CC BY-SA license.

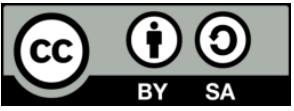

Corresponding Author:

Ali Abdulateef Abdulbari

Wireless Communication Centre (WCC)

School of Electrical Engineering

Universiti Teknologi Malaysia (UTM)

Skudai 81310, Malaysia

Email: alilateefutm@gmail.com

\section{INTRODUCTION}

The branch-line coupler (BLC) is an important component in the microwave integrated circuit such as power divider, modulators, phase shifter and feeding network to beamforming network. It has the ability to divide the power equally/unequally with a $90^{\circ}$ phase difference between the output through and the coupled port. The traditional BLC is easily implemented using a quarter-wave transmission line (QWTLs) that includes the impedance of $\mathrm{Zo} / \sqrt{2}=35.35 \Omega$ and $\mathrm{Zo}=50 \Omega$ [1]. The conventional BLC single section is realized by the $\lambda / 4$ microstrip line (QWLMLs) by three lines as $90^{\circ}$ transmission lines, one $180^{\circ}$ transmission line, one $-90^{\circ}$ transmission line with specified characteristic impedance $[2,3]$. 
The major issues in conventional BLCs are the large size of $\lambda / 4$ and the narrow bandwidth of 10\%-20\% [4] which limits their usage. Many techniques have been proposed to overcome these issues such as using cascading [5] and a T-shaped transmission line, which reduces the size by 55\% [6]. The regular microstrip BLC is replaced with a lumped circuit, made from two open stubs by a series of transmission line (TL) [7], and it reduces the size of BLC to $55.2 \%$ with a fractional bandwidth of $56 \%$ based on the lumped element method, fractal geometry [8], three-section branch-line hybrid [9], a multilayer [10], a meander line [11], and a dual-band branch-line coupler [12]. Various techniques have been employed to miniaturize the size of the microwave component (s), to reduce the BLC size and to increase the bandwidth. Therefore, the size reduction is very important for developing the high-performance radio frequency, and stringent requirements should be in place for the future microwave communication systems [13].

In this study, a compact new design for a wideband BLC using a T-shape and an open stub on the TL is proposed. The transmission line consists of a horizontal open-stub with a slot of T-shape and a vertical T-shape connected to the center of the TL. The symmetrical T-shape transmission line is one of the best methods to realized microwave as in [14]. The proposed BLC wideband (QWTL) structure hasthe capability to achieve a wideband frequency ratio operation. The overall proposed structure is simulated by using CST Microwave Studio and fabricated using a cheap substrate material of FR-4. A good agreement between the simulation and measurement results was obtained throughout the 2.9 to $4 \mathrm{GHz}$ frequency band.

\section{THEORETICAL ANALYSIS TRANSMISSION LINE}

\subsection{Mixed-mode S-parameters of the BLC}

In this part, scattering parameters integrated with the $\mathrm{ABCD}$ matrix of the circuit proposal were employed to obtain the analysis solution as SSB, SSE and SSD are to describe the S-parameters as in [15]. The proposed branch-line coupler (BLC) is a single section consisting of four ports, and the stander scattering matrix $\left[\mathrm{S}^{\mathrm{BLC}}\right]$ can be expressed as follows:

$$
\left[S^{B L C}\right]=\left[\begin{array}{cccc}
S_{11} & S_{12} & S_{13} & S_{14} \\
S_{21} & S_{22} & S_{23} & S_{24} \\
S_{31} & S_{32} & S_{33} & S_{34} \\
S_{41} & S_{42} & S_{43} & S_{44}
\end{array}\right]
$$

The relationship between the mixed-mode $\left[\mathrm{S}^{\mathrm{MD}}\right]$ and the scattering matrix $\left[\mathrm{S}^{\mathrm{BLC}}\right]$ of the proposed branch-line coupler (BLC) has been reported as in [15].

$$
\begin{aligned}
& {\left[S^{M D}\right]=[M T]\left[S^{B L C}\right]\left[M T^{-1}\right]}
\end{aligned}
$$

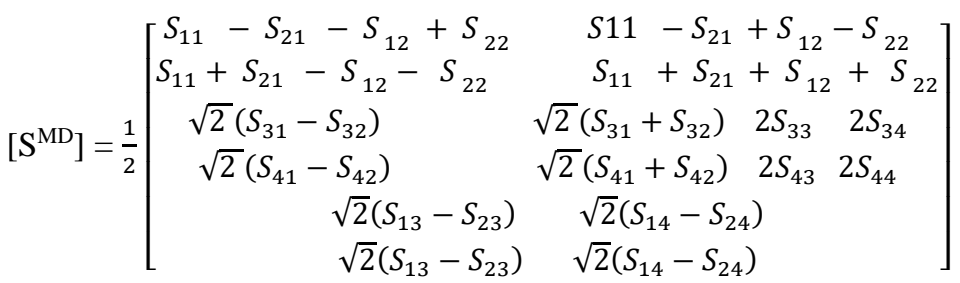

The matrix equation [MT] is a standard of S-parameters used in the proposed BLC and can be expressed as follows:

$$
[\mathrm{MT}]=\frac{2}{\sqrt{2}}\left[\begin{array}{cccc}
1- & 1 & 0 & 0 \\
1 & 1 & 0 & 0 \\
0 & 0 & \sqrt{2} & 0 \\
0 & 0 & 0 & \sqrt{2}
\end{array}\right]
$$

\section{STRUCTURE OF PROPOSED BLC USING T-SHAPE AND OPEN STUB TL}

The quarter wavelength of the transmission line BLC is known to have a narrow bandwidth and bulky size, as shown in Figure 1(a), the size of the branch-line coupler (BLC) considering the major issues. Figure 1(b) shows the $\mathrm{Z}_{0}$ as well as the $\theta$ o characteristic impedance and the electrical length of the BLC. The layout of the symmetrical T-shape TL, consists of two series transmission lines (Za1, , a 1) and the shuntopen stub $\left(Z_{\mathrm{b} 2}, \theta_{\mathrm{b} 2}\right)$. The design equation of the T-shape model is given by [16] and can be expressed as follows:

$$
Z_{a 1}=Z \cot \frac{\theta_{a 1}}{2}
$$




$$
Z_{b 1}=\frac{Z_{a 1}}{2} \tan \theta_{a 1} \tan \theta_{b 2}
$$

$\mathrm{Z}$ is the characteristic impedance $\Omega$ of the BLC. The T-shape model BLC achieves a compact size when $\theta \mathrm{a} 1$ is $<90^{\circ}$. However, when the series arm impedance $Z_{\mathrm{a} 1}$ increases, the series arm length $\theta \mathrm{a} 1$ will decrease, while the shunt impedance $Z_{b 1}$ decreases for a constant stub length $\theta_{b 1}$. The present equivalent circuit of the conventional branch-line coupler is depicted in Figure 1 (c) and Figure 1(d).

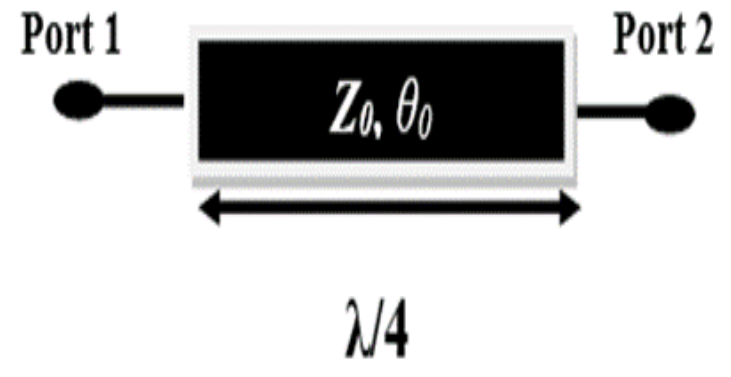

(a)

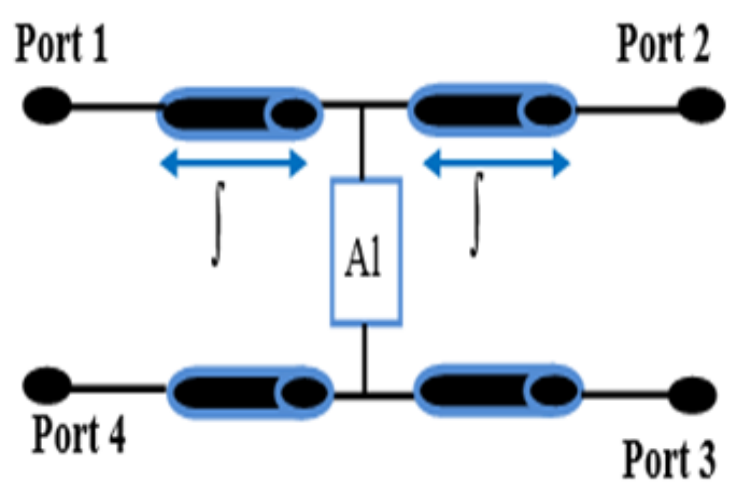

(c)

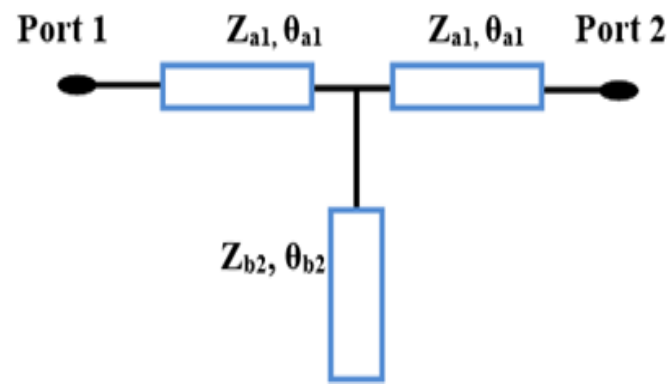

(b)

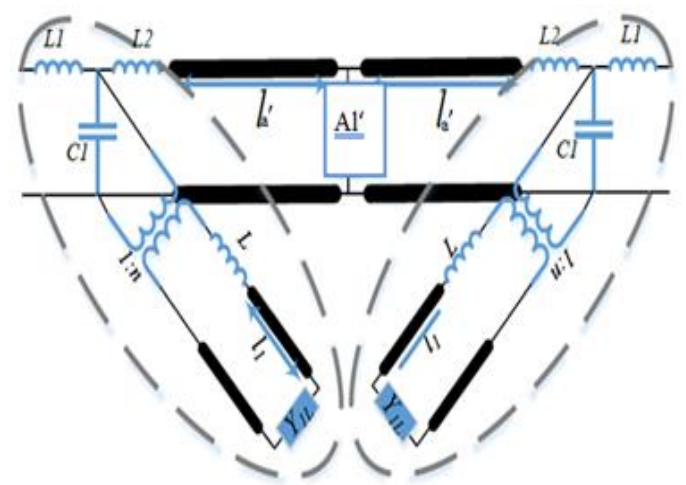

(d)

Figure 1. (a) Formal $90^{\circ}$ branch-line coupler, (b) equivalent circuit of $\lambda / 4$ transmission line T-shape model, (c) conventional transmission line, (d) equivalent circuit of the quarter wavelength $\lambda / 4$ transmission line

The scattering parameters of the four-BLC ports, $S_{11}, S_{21}, S_{31}, S_{41}$, are expressed in term of even and odd reflection coefficients $\Gamma_{\mathrm{ee}}, \Gamma_{\mathrm{eoo}}, \Gamma_{\mathrm{ooe}}$ and $\Gamma_{\mathrm{oo}}$ which can be expressed as follows:

$$
\begin{aligned}
& \mathrm{S}_{11}=\frac{\Gamma_{\mathrm{ee}}+\Gamma_{\mathrm{oee}}+\Gamma_{\mathrm{oo}}+\Gamma_{\mathrm{eoo}}}{4} \\
& \mathrm{~S}_{21}=\frac{\Gamma_{\mathrm{ee}}-\Gamma_{\mathrm{oee}}-\Gamma_{\mathrm{oo}}+\Gamma_{\mathrm{eoo}}}{4} \\
& \mathrm{~S}_{31}=\frac{\Gamma_{\mathrm{ee}}-\Gamma_{\mathrm{oee}}+\Gamma_{\mathrm{oo}}-\Gamma_{\mathrm{eoo}}}{4} \\
& \mathrm{~S}_{41}=\frac{-\Gamma_{\mathrm{ee}}-\Gamma_{\mathrm{oee}}+\Gamma_{\mathrm{oo}}+\Gamma_{\mathrm{eoo}}}{4}
\end{aligned}
$$

The characteristic impedance, for example $Z_{0}=50 \Omega, Z_{1}=139.7 \Omega, Z_{2}=54 \Omega, Z_{3}=58.3 \Omega$ and electrical length $\theta_{1}=\theta_{2}=\theta_{3}=90^{\circ}$ [17]. The BLC single section is printed on the substrate from FR $-4, \varepsilon_{\mathrm{r}}=4.4$, loss tangent, $\tan \delta=0.025$, and $\mathrm{h}=1.6 \mathrm{~mm}$. The primary resistances of the main-line of the BLC are $\mathrm{Z}_{1}, \mathrm{Z}_{2}$, and $\mathrm{Z}_{3}$. The electrical length $\theta_{1}, \theta_{2}$, and $\theta_{3}$ is the main-line for BLC. Port 1 is an input, port 2 and port 3 are outputs, while port 4 is an isolation port. The width of the microstrip transmission line at $3.5 \mathrm{GHz}$ at the center frequency was calculated from the (8) and can be expressed as follows: 


$$
W=\left\{\begin{array}{cc}
\frac{8 h \mathrm{e}(A)}{e(2 A)-2} & \text { for } \frac{W}{h}<2 \\
\frac{2 h}{\Pi}\left\{\begin{array}{l}
\left.B-1-\ln (2 B-1)+\frac{\varepsilon r-1}{2 \varepsilon r}\right) \\
{\left[\operatorname{In}(B-1)+0.39-\frac{0.61}{\varepsilon r}\right]}
\end{array}\right\} & \text { for } \frac{W}{h}>2
\end{array}\right.
$$

Where

$$
\begin{aligned}
& \mathrm{A}=\frac{Z_{N}}{60} \sqrt{\frac{\varepsilon r+1}{2}}+\frac{\varepsilon r-1}{\varepsilon r+1}\left(0.025+\frac{0.11}{\varepsilon r}\right) \\
& B=\frac{376.73 \Pi}{2 z_{n} \sqrt{\varepsilon r}}
\end{aligned}
$$

$Z_{N}$ is the impedance characteristic of the microstrip line and the subscript $\mathrm{N}$ refers to the number of ports; $0,1,2$, and 3 . The length of the microstrip transmission line from the quarter wavelength $\lambda / 4$ of the BLC has been reported in [1] and was calculated from the (11), which can be expressed as follows:

$$
L=\frac{c}{4 f_{0} \sqrt{\varepsilon e f f}}-0.412 h\left[\frac{\varepsilon e f f+0.3)\left(\frac{w}{h}+0.264\right)}{\left.\sum e f f-0.258\right)\left(\frac{w}{h}+0.8\right)}\right]
$$

The velocity of light in space is c=186, 282 miles per second, and the effective permittivity Eeff, of the BLC microstrip line, was obtained as in [18] and can be expressed as follows:

$$
\varepsilon_{\text {eff }}=\left\{\begin{array}{c}
\frac{\varepsilon r+1}{2}+\frac{\varepsilon r-1}{2}\left[\frac{1}{\sqrt{1+\frac{12 h}{W}}}+0.04\left(1-\frac{W}{h}\right) 2\right] \text { for } W / h \leq 1 \\
\frac{\varepsilon r+1}{2}+\frac{\varepsilon r-1}{2}\left(\frac{1}{\sqrt{1+12 h / W}}\right) \text { for } W / h>1
\end{array}\right\}
$$

Through the even-odd mode analysis, S-parameters of the reflection coefficient to the transmission line (TL) can be expressed in [19]. $\Gamma$ is the reflection coefficient and $\mathrm{T}$ is the transmission line coefficient, meanwhile can be expressed as follows:

$$
\begin{aligned}
& \Gamma=\frac{a^{\prime}+\frac{b^{\prime \prime}}{Z_{0}}-C Z_{0}-d}{a^{\prime}+\frac{b^{\prime \prime}}{Z_{0}}+C Z_{0}+d} \\
& \mathrm{~T}=\frac{2}{a^{\prime}+\frac{b^{\prime \prime}}{Z_{0}}+C Z_{0}+d}
\end{aligned}
$$

\section{PROPOSED DESIGN BLC WITH T-SHAPE AND OPEN STUB}

To overcome the major issues of the narrow bandwidth and the bulky size of the BLC, the proposed $\mathrm{T}$-shape and an open stub were used to replace a conventional $\lambda / 4$ of the transmission line. Figure 2 shows the simulated design of the proposed BLC where a compact design T-shape and an open stub were used. As shown in Figures 2(a) and (b), T-shaped slots were introduced to replace a conventional (QWTL) BLC design. In the proposed design layout, the author also introduced the equivalent open stub design with an open stub with a T-shape model and T-shape model structure to the proposed layout in order to give a better performance in the designas shown in Figure 2(c) and (d). The T-shape approach was adopted to reduce the size of the transmission line $\lambda / 4$ and miniaturize the microstrip of the BLC. The impedances of the horizontal and vertical of the branch-line coupler (BLC) are $35.36 \Omega$ and $50 \Omega$. Meanwhile, the output of the phase difference of the quadrature wavelength of the BLC is $90^{\circ}$, and the electrical length of the BLC is $\theta 2=\theta 3=90^{\circ}$. All the impedances and optimized parameters for the BLC are presented in Figure 2.

The Agilent vector network analyzer was used to test the performance of the proposed BLC while as to ensure that the proposed BLC design achieved good performance and was compared with the simulated result. Figure 3 shows the experimental setup for the S-parameters measurement setting of the proposed BLC. The network analyzer was used to measure $S_{11}, S_{21}, S_{31}$, and $S_{41}$ with a frequency ranging from $2 \mathrm{GHz}$ to $5 \mathrm{GHz}$. Table 1 presents all dimensions of the proposed BLC. 


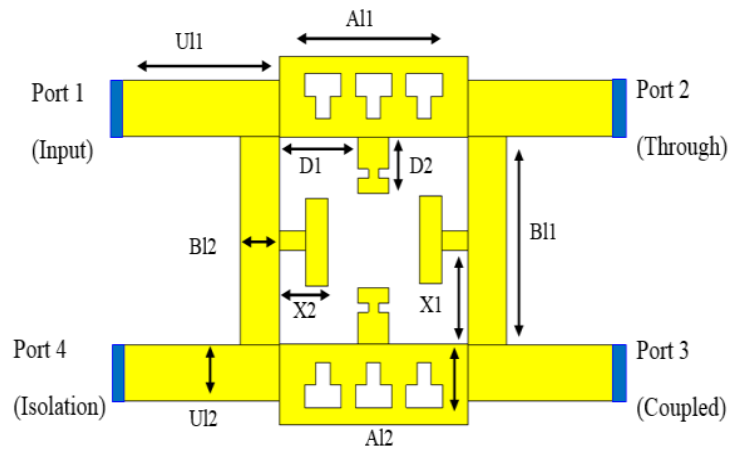

(a)

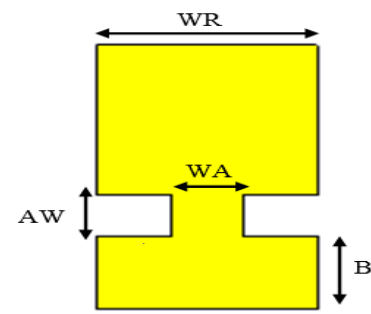

(c)

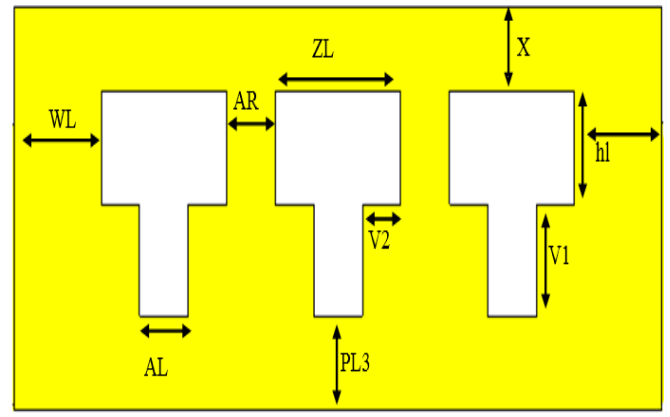

(b)

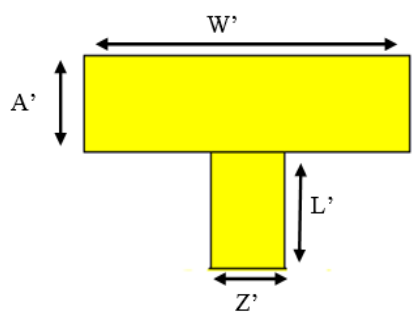

(d)

Figure 2. The simulated design of the proposed BLC, (a) layout of branch-line coupler compact size, (b) equivalent $\mathrm{T}$ - shape slot structure, (c) equivalent open stub with $\mathrm{T}$ - shape model, (d) equivalent $\mathrm{T}$ - shape model structure

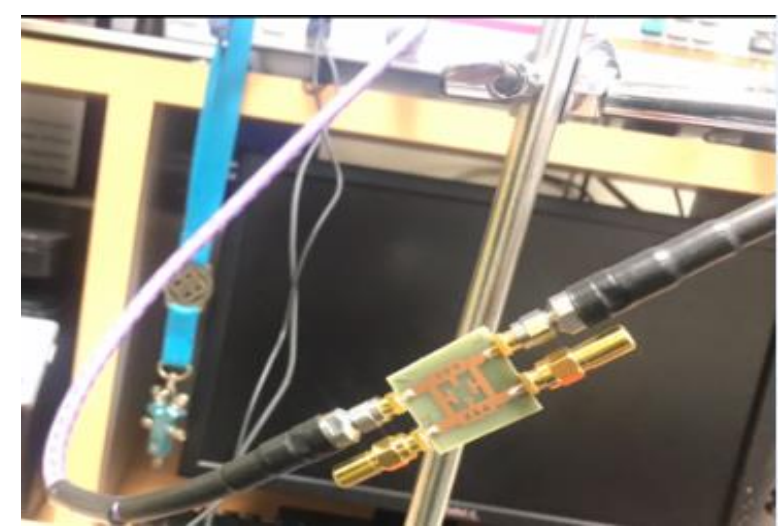

Figure 3. Photograph of BLC under test S-parameters

Table 1. The dimension of the proposed branch-line coupler with T-shape model all dimension (mm)

\begin{tabular}{cccc}
\hline Parameters & Value & Parameters & Value \\
\hline Z1 & $35.36 \Omega$ & V1 & 1 \\
Z2 & $50.00 \Omega$ & V2 & 0.55 \\
$\theta_{1}$ & $90^{\circ}$ & AR & 0.7 \\
$\theta_{2}$ & $90^{\circ}$ & AL & 0.7 \\
$\theta_{3}$ & $90^{\circ}$ & WL & 1.28 \\
A11 & 9.4 & PL3 & 0.93 \\
A12 & 3.5 & X & 1.46 \\
B11 & 9.3 & h & 1 \\
B12 & 1.9 & WR & 1.5 \\
U11 & 8.9 & B & 0.69 \\
U12 & 2.5 & AW & 0.41 \\
D1 & 3.9 & WA & 0.5 \\
D2 & 2.5 & W' & 3.9 \\
X1 & 4.19 & A' & 1.1 \\
X2 & 2.83 & L' & 1.31 \\
ZL & 1.8 & Z' & 0.87 \\
\hline
\end{tabular}




\section{DESIGN I}

As for the design (I) showed in Figure 4, the author had designed a conventional BLC by using all the calculated parameters obtained through the (11) for obtaining the length of TL and the (8) in obtaining the width of TL. All of the parameters were obtained by tuning the center frequency at $3.5 \mathrm{GHz}$ and by using the characteristic of the material used which is FR-4. The final dimension obtained is as follows: A $1=10 \mathrm{~mm}$, $\mathrm{A} 2=4.5 \mathrm{~mm}, \mathrm{~B} 1=10.3 \mathrm{~mm}, \mathrm{~B} 2=2.5 \mathrm{~mm}, \mathrm{C} 1=0 \mathrm{~mm}, \mathrm{C} 2=2.5 \mathrm{~mm}$. The occupied area of the proposed coupler is of the design (I) is $0.29 \lambda \mathrm{g} \times 0.17 \lambda \mathrm{g}\left(29 \times 17 \mathrm{~mm}^{2}\right)$. The simulation result of design (I) is presented in Figure 5. The results show that the differential mode impedance matches, where the return loss $S_{11}$ value is $-26.4 \mathrm{~dB}$ at the $3.4 \mathrm{GHz}$ operating frequency and their isolation $\mathrm{S}_{41}$ value are $-28.68 \mathrm{~dB}$ at the $3.43 \mathrm{GHz}$. Additionally, the coupling factor $\mathrm{S}_{21}$ of design (I) and the insertion loss $\mathrm{S}_{31}$ is equal to $-3.5 \mathrm{~dB}$ and $-3.1 \mathrm{~dB}$, respectively. Figure 5 also shows that the fractional bandwidth is $24.42 \%$ from $2.9 \mathrm{GHz}$ to $3.7 \mathrm{GHz}$. Figure 6 shows the measured phase difference between the output ports through $S_{21}$ and coupled $S_{31}$. It indicates that design (I) is able to couple the signal diagonally from the input to the output at $3 \mathrm{GHz}$.

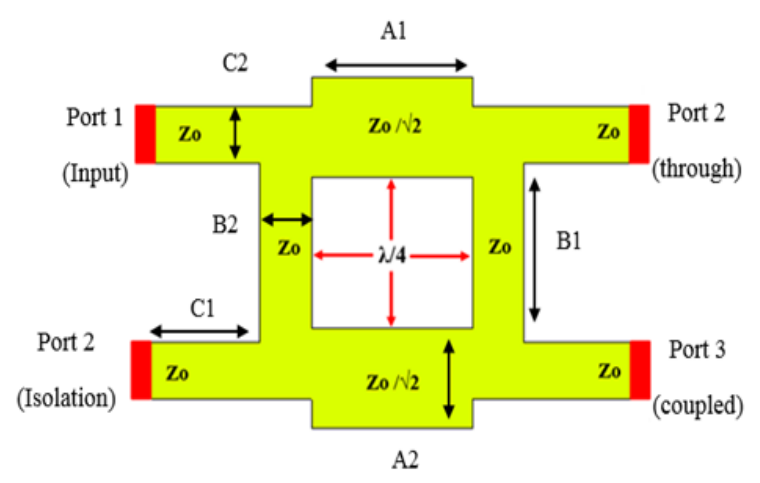

Figure 4. Conventional structure for branch-line coupler

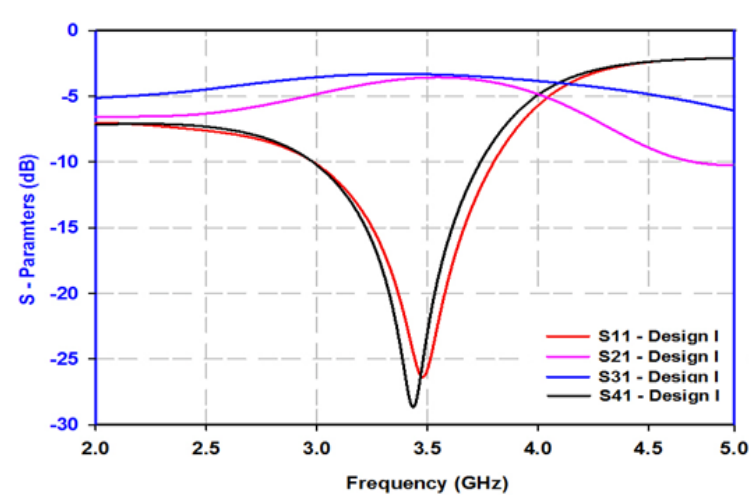

Figure 5. The conventional frequency response of the BLC S11, S21 S31 and S41

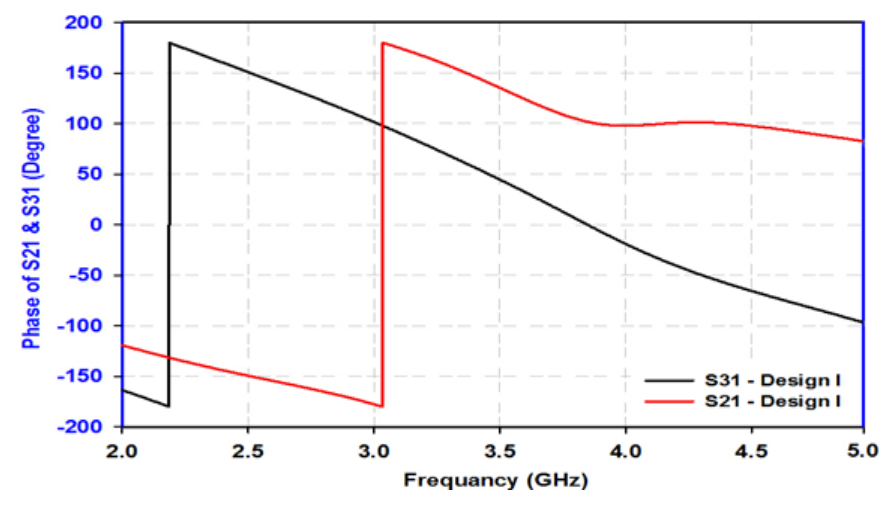

Figure 6. The phase of the design (I) BCL between S21 and S31

\section{DESIGN II}

Design (II) is the response of the microstrip BLC using the slot T-shape and an open stub with high and low impedance wavelength on the horizontal wavelength transmission line $35.36 \Omega$ as discussed in the previous section (3). Clearly, the proposed BLC enhances the bandwidth for the impedance matching in design (II) through the implementation of the T-shape and the open stub techniques. From Figure 7, the value of the return loss $\mathrm{S}_{11}$ for the proposed design is $-30.69 \mathrm{~dB}$ at the center frequency of $3.5 \mathrm{GHz}$. This figure also indicates that the isolation factors obtained at the operating frequency of $3.5 \mathrm{GHz}$ band is equal to $-29.28 \mathrm{~dB}$. Additionally, the coupling factor $S_{21}$ and the insertion loss $S_{31}$ of the proposed design are at -2.97 and $-3.65 \mathrm{~dB}$, respectively. From the result shown in Figure 7, the introduction of the T-shape and the open stub in the proposed design wide the bandwidth value, wherein this design the fractional bandwidth is $2.9 \mathrm{GHz}-4 \mathrm{GHz}$, which is equal to $32.29 \%$. This data clearly indicates that the introduction of the slotting and the stub 
techniques within the BLC design can widen the bandwidth value. The bandwidth was calculated using (15) and can be expressed as follows:

$$
\text { Bandwidth }(\mathrm{BW})=\frac{\mathrm{f}_{2}-\mathrm{f}_{1}}{\sqrt{\mathrm{f}_{2} \times \mathrm{f}_{1}}} \times 100 \%
$$

The simulated result of the proposed design (II) has a good agreement on the frequency of $3.5 \mathrm{GHz}$. Figure 8 shows the different phases of two output ports, $S_{21}$ and $S_{31}$ of the proposed BLC. Figure 9 shows the measurement result of the proposed design (II). The results signify that the range operating bandwidth is between $3 \mathrm{GHz}$ to $4.1 \mathrm{GHz}$ where it gives $31 \%$ bandwidth values, where the return loss $\mathrm{S}_{11}$ and isolation $\mathrm{S}_{41}$ are $-27.47 \mathrm{GHz}$ and $-26.2 \mathrm{GHz}$ respectively. Meanwhile, the through $\mathrm{S}_{21}$ and coupled $\mathrm{S}_{31}$ values are equal to $-4.4 \mathrm{~dB}$ and $-4.1 \mathrm{~dB}$, respectively. Figure 10 shows the fabricated proposed BLC using the T-shape with the open stub.

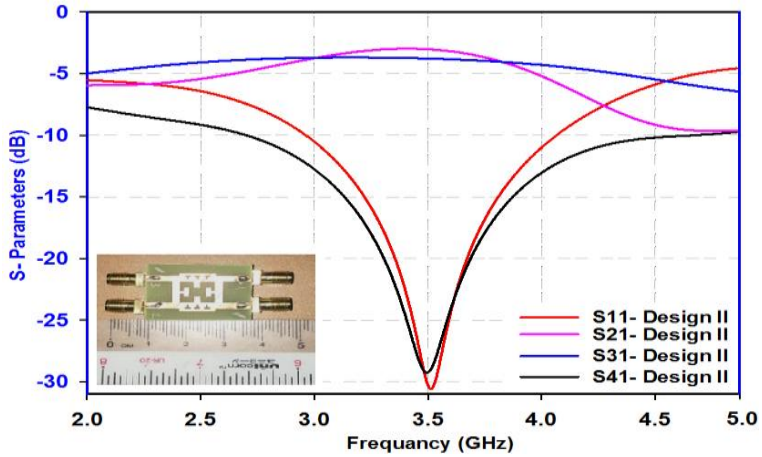

Figure 7. The simulation frequency response of the proposed branch-line coupler S11, S21, S31, S41

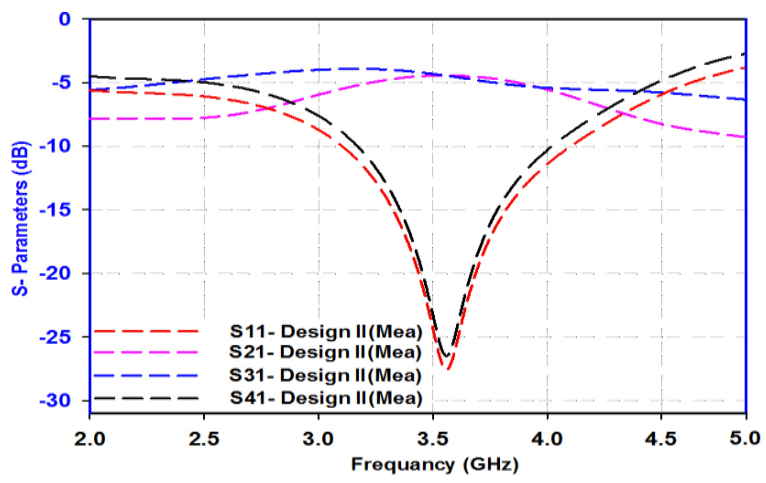

Figure 9. The measurement result of the proposed design II

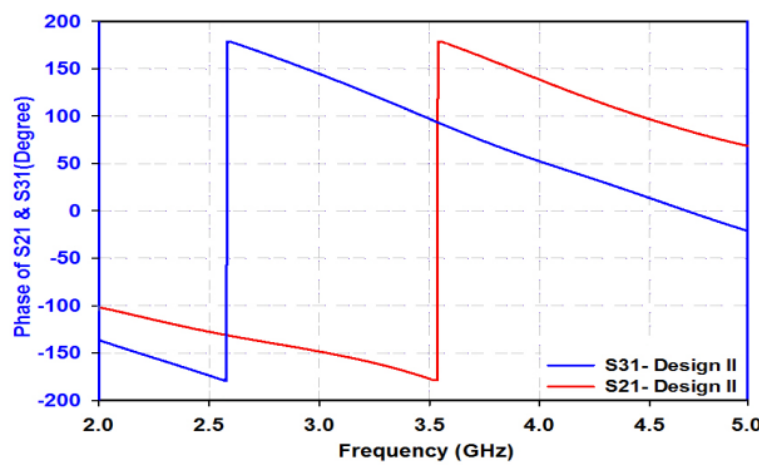

Figure 8 . The phase of the design II of two output ports S21 and S31

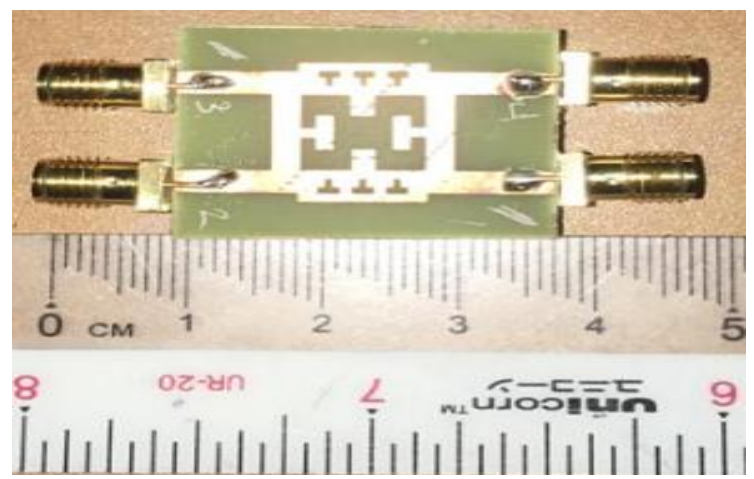

Figure 10. Fabrication of the proposed BLC

\section{VALIDATION}

\subsection{Comparison between design (I) and desin (II)}

This section discusses the comparison structure analysis of the single section of design (I) and design (II) of the BLC. Figure 11 shows the difference between the conventional design (I) and the proposed design (II), using the techniques of the T-shape and the open stub on the horizontal and vertical arm transmission lines of design (II). Moreover, the results show that the fractional bandwidth has been improved from $24.42 \%$ to $32.29 \%$ and the shifting of the signal from the frequency $3.43 \mathrm{GHz}$ to $3.5 \mathrm{GHz}$ as a desired operating frequency. The results of the coupling factor between two ports, $S_{21}$ and $S_{31}$ for the conventional design (I) and the proposed design (II) increased from (-3.5 and -3.1$) \mathrm{dB}$ to (-2.97 and -3.65$) \mathrm{dB}$ respectively, as shown in Figure 12. As for Figure 13, it demonstrates a simulation for the conventional design (I) and the proposed design (II) of the phase difference between ports $S_{21}$ and $S_{31}$ respectively. 


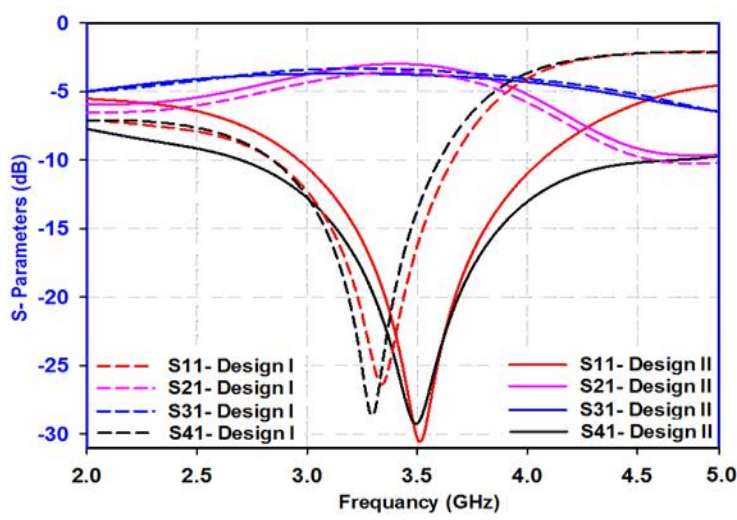

Figure 11. Comparison of the design (I) and design (II)

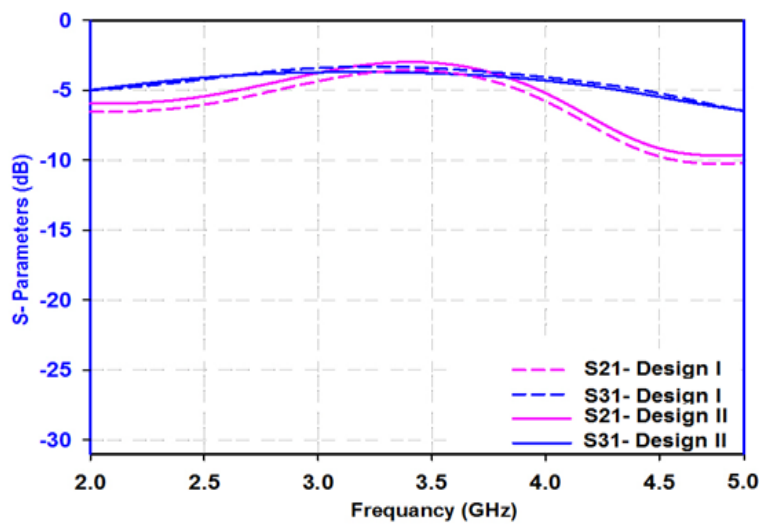

Figure 12. Comparison of the coupling factor (S21 and S31) of the design (I) and design (II)

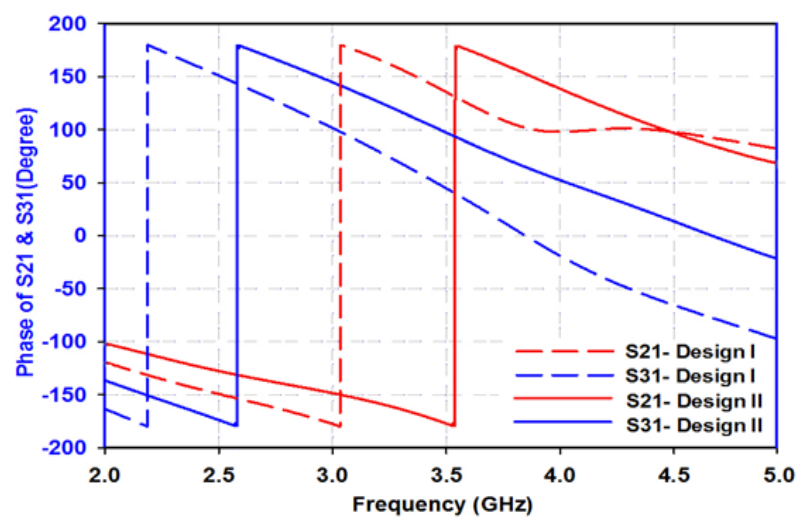

Figure 13. Comparison phase of the design (I) and design (II) for (S21) and (S31)

\subsection{Comparison of the simulation and measurement result in the proposed design (II)}

The comparison of the simulation and measurement result of design II is shown in Figure 14. According to the result shown, it was interpreted that the simulated and measured data is in good agreement. Figure 15 shows that the amplitude imbalance and the phase difference between two output ports for the simulation and measurement are approximately $\pm 0.1 \mathrm{~dB}$ and $90^{\circ} \pm 3.54^{\circ}$ and $90^{\circ} \pm 3^{\circ}$ respectively.

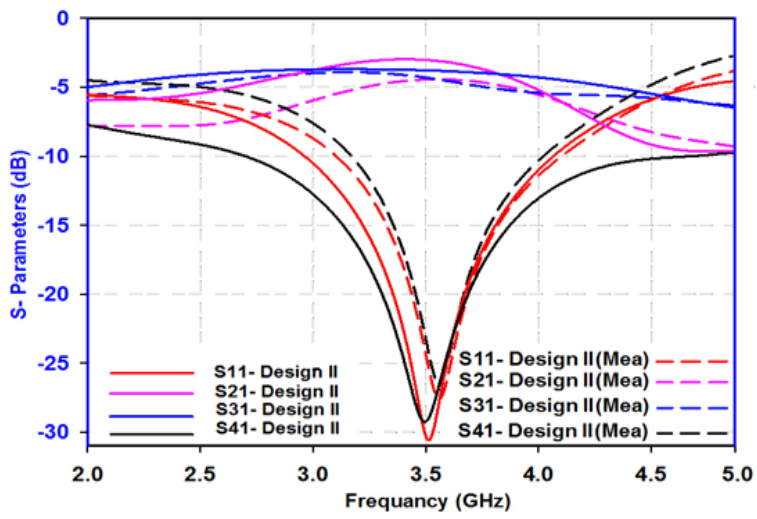

Figure 14. Comparison of the simulation and measurement for design (II)

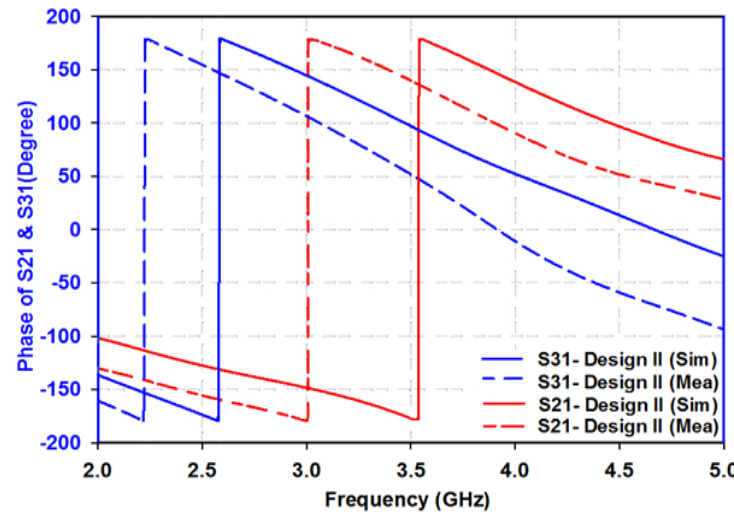

Figure 15. Comparison phase of the simulation and measurement for design (II) 


\subsection{Comparison of the simulation design (I) design (II) and measurement design (II)}

This section shows a comparison of the simulation and measurement between design I and design (II) as shown in Figure 16. While Table 2 shows a comparison of the conventional design I and proposed design (II). All the data from Figure 16 is tabulated in Table 2. As can be seen, the proposed design gives a better return loss S11 and isolation S41 values where it gives $-30.69 \mathrm{~dB}$ and $-29.28 \mathrm{~dB}$ at center frequency 3.5 GHz. The table also clearly shows the effect of T-shape and stub techniques on miniaturizing the size of the proposed design. Table 3 shows a comparison of the proposed BLC design performance with previous researches in terms of their isolation, return loss, coupling factor, insertion loss, and phase shift values respectively. This table shows that the proposed BLC design is comparable with previous work although the proposed design implementing less complex structure.

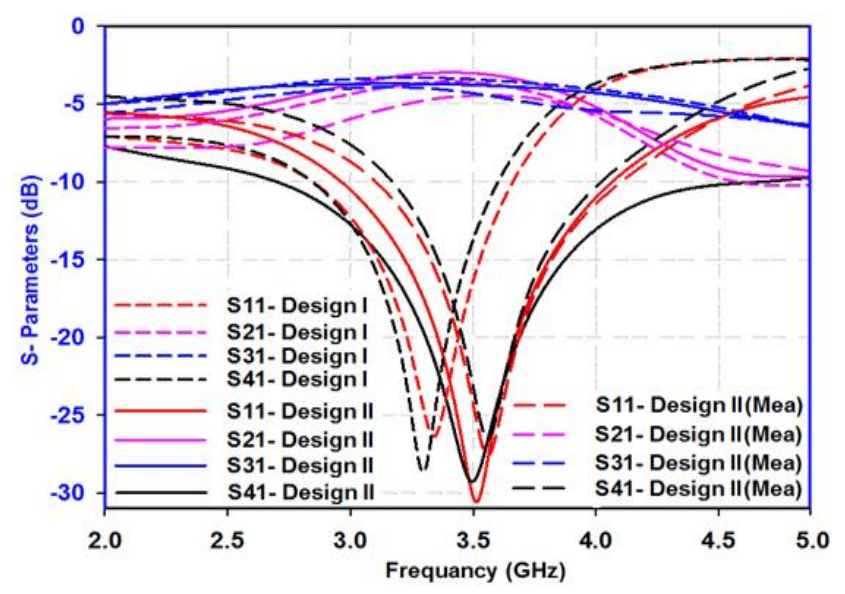

Figure 16. Comparison of the simulation design (I) design (II) and measurement design (II)

Table 2. Comparison of the conventional design (I) and proposed design (II)

\begin{tabular}{ccccccccc}
\hline Parameters & $\begin{array}{c}\text { Frequency } f_{o} \\
(\mathrm{GHz})\end{array}$ & $\begin{array}{c}\text { Return loss } \\
\left(\mathrm{S}_{11}\right)\end{array}$ & $\begin{array}{c}\text { Through } \\
\left(\mathrm{S}_{21}\right)\end{array}$ & $\begin{array}{c}\text { Coupled } \\
\left(\mathrm{S}_{31}\right)\end{array}$ & $\begin{array}{c}\text { Isolation } \\
\left(\mathrm{S}_{41}\right)\end{array}$ & $\begin{array}{c}\text { Bandwidth } \\
(\mathrm{dB})\end{array}$ & $\begin{array}{c}\text { Size } \\
\left(\lambda_{g} \times \lambda_{g}\right)\end{array}$ \\
\hline Design I & 3.4 & -26.4 & -3.5 & -3.1 & -28.4 & $24.42 \%$ & $0.29 \lambda_{g} \times 0.17 \lambda_{g}$ \\
Design II (simulation) & 3.5 & -30.69 & -2.97 & 3.65 & -29.28 & $32.29 \%$ & $0.27 \lambda_{g} \times 0.16 \lambda_{g}$ \\
Design II (Measurement) & 3.55 & -27.47 & -4.4 & -4.1 & -26.2 & $31 \%$ & 0 \\
\hline
\end{tabular}

Table 3. Comparison of the previous state to the BLC conventional design (I) and proposed design (II)

\begin{tabular}{|c|c|c|c|c|c|c|c|}
\hline Ref & Technology & Frequency $(\mathrm{GHz})$ & $\mathrm{S}_{11}(\mathrm{~dB})$ & $\mathrm{S}_{21}(\mathrm{~dB})$ & $\mathrm{S}_{31}(\mathrm{~dB})$ & $\mathrm{S}_{41}(\mathrm{~dB})$ & Phase shift \\
\hline$[6]$ & Dual feed and T-shape & 3 & 21 & 1.02 & - & 22 & $90^{\circ}$ \\
\hline [21] & T-model with open stubs & 2.45 & 21.7 & 3.2 & 3.1 & 36.6 & 0.1 \\
\hline [23] & Microstrip line & 3 & 16.3 & 1.0 & 0.25 & 18.7 & $90^{\circ}$ \\
\hline [24] & Meander T-shape line & 2.1 & 46.9 & 3.08 & 3.19 & 35.6 & - \\
\hline [25] & Spirals and Step Impedance & 3 & 17 & 3.02 & 3.16 & 34 & $0.49^{\circ}$ \\
\hline
\end{tabular}

\section{CONCLUSION}

This paper proposed a compact new design for a single-section wideband 3-dB BLC with a vertical slot T-shape on the TL connected with two open-stubs and a horizontal print T-shape quarter wavelength transmission line. The proposed BLC was designed using the right/left-handed transmission line. The design I of the BLC was a conventional design as validation with the enhanced structure in design (II). The proposed design (II) had the compact size of $27 \times 16 \mathrm{~mm}\left(0.27 \lambda \mathrm{g} \times 0.16 \lambda \mathrm{gmm}^{2}\right)$ and improved the bandwidth from $24.42 \%$ to $32.29 \%$. The results showed that the simulation and measurement of return loss, insertion loss and phase shift between ports had a good agreement with design (II) BLC $\lambda / 4$ transmission line. The application of the proposed BLC design in this study can be used for future studies in the $5 \mathrm{G}$ wireless communication system. 


\section{ACKNOWLEDGEMENTS}

The authors would like to thank to FRGS funding body to support the project title "New design of wideband microstrip branch line coupler using T-shape and open stub for 5G application" (grant no. FRGS/7/2020/TK08/MMU/02/1).

\section{REFERENCES}

[1] S. Reshma and M. K. Mandal, "Miniaturization of a $90^{\circ}$ Hybrid Coupler with Improved Bandwidth Performance," IEEE Microwave and Wireless Components Letters, vol. 26, no. 11, pp. 891-893, 2016.

[2] J. Shi, J. Qiang, Q. Cao, W. Zhang, and J. Chen, "An Enabling Multi-Operation Branch-Line Coupler," IEEE Access, vol. 7, pp. 10374-10382, 2019.

[3] M. Alibakhshikenari, B. S. Virdee, C. H. See, R. A. Abd-Alhameed, F. Falcone, and E. Limiti, "High-Gain Metasurface in Polyimide On-Chip Antenna Based on CRLH-TL for Sub-Terahertz Integrated Circuits," Scientific Reports, vol. 10, no. 4298, pp. 1-9, 2020.

[4] N. N. Al-Areqi, K. Y. You, N. H. Khamis, M. N. Dimon, and C. Y. Lee, "Miniaturization of three-section branchline coupler using diamond-series stubs microstrip line," Progress In Electromagnetics Research C, vol. 82, pp. 199-207, 2018.

[5] W. A. Arriola, J. Y. Lee, and I. S. Kim, "Wideband $3 \mathrm{~dB}$ branch line coupler based on $\lambda / 4$ open circuited coupled lines," in IEEE Microwave and Wireless Components Letters, vol. 21, no. 9, pp. 486-488, 2011.

[6] M. Kumar, S. K. N. Islam, G. Sen, S. K. Parui, and S. Das, "Design of miniaturized $10 \mathrm{~dB}$ wideband branch line coupler using dual feed and T-shape transmission lines," Radioengineering, vol. 27, no. 1, pp. 207-213, 2018.

[7] O. Kazan, O. Memioglu, F. Kocer, A. Gundel, and C. Toker, "A Lumped-Element Wideband 3-dB Quadrature Hybrid," in IEEE Microwave and Wireless Components Letters, vol. 29, no. 6, pp. 385-387, 2019.

[8] M. Kumar, S. K. N. Islam, G. Sen, S. K. Parui, and S. Das, "Design of miniaturized $10 \mathrm{~dB}$ wideband branch line coupler using dual feed and T-shape transmission lines," Radioengineering, vol. 27, no. 1, pp. 207-213, 2018.

[9] R. K. Barik, R. Rajender, and S. S. Karthikeyan, "A miniaturized wideband three-section branch-line hybrid with harmonic suppression using coupled line and open-ended stubs," in IEEE Microwave and Wireless Components Letters, vol. 27, no. 12, pp. 1059-1061, 2017.

[10] D. N. A. Zaidel, S. K. A. Rahim, N. Seman, C. L. Chew, "A Design of Octagon-Shaped 3-dB Ultra Wideband Coupler Using Multilayer Technology," Microwave and Optical Technology Letters, vol. 55, no. 1, pp. 748-753, 2013.

[11] B. M. Sa'ad, Sharul K.A. Rahim, "Compact Wide-Band Branch-Line Coupler with Meander Line, Cross, And Two-Step Stubs,” Microwave and Optical Technology Letters, vol. 55, no. 8, pp. 1810-1815, 2013.

[12] A. M. Zaidi, M. T. Beg, B. K. Kanaujia, K. Srivastava, and K. Rambabu, "A Dual Band Branch Line Coupler With Wide Frequency Ratio," IEEE Access, vol. 7, pp. 25046-25052, 2019.

[13] K. V. Phani Kumar and S. S. Karthikeyan, "Miniaturised quadrature hybrid coupler using modified T-shaped transmission line for wide-range harmonic suppression," in IET Microwaves, Antennas \& Propagation, vol. 10, no. 14, pp. 1522-1527, 2016.

[14] V. K. Velidi, A. Pal, and S. Sanyal, "Harmonics and size reduced microstrip branch-line baluns using shunt openstubs," International Journal of RF and Microwave Computer-Aided Engineering, vol. 21, no. 2, pp. 199-205, 2011.

[15] W. R. Eisenstadt and B. Stengel, "Microwave Differential Circuit Design Using Mixed-Mode S Parameters," Artech House, 2006.

[16] R. Florencio Díaz, et al., "Broadband reflectarrays made of cells with three coplanar parallel dipoles," Microwave and Optical Technology Letters, vol. 50, no. 11, pp. 2812-2814, 2008.

[17] K. Y. You, N. Al-Areqi, J. C. Chong, K. Y. Lee, E. M. Cheng, and Y. S. Lee, "Analytical modeling of conventional and miniaturization three-section branch-line couplers," Journal of Electrical Engineering and Technology, vol. 13, no. 2, pp. 858-867, 2018.

[18] D. M. Pozar, "Microwave Engineering," 4th ed. Wiley, Hoboken, N. J., 2011.

[19] D. Pozar, "Microwave Engineering," USA: Wiley, Hoboken, N. J., 2009.

[20] M. Ali, S. K. A. Rahim, M. Z. M. Nor, and M. F. Jamlos, "Branch Line Coupler Using Hybrid T-Model Structure," Microwave and Optical Technology Letters, vol. 54, no. 1, pp. 237-240, 2012.

[21] M. Y. O. Elhiwaris, S. K. A. Rahim, U. A. K. Okonkwo and N. M. Jizat, "Miniaturized Size Branch Line Coupler Using Open Stubs with High-Low Impedances," Progress In Electromagnetics Research Letters, vol. 23, pp. 65-74, 2011.

[22] A. Rezaei, L. Noori, and S. M. Hosseini, "Novel microstrip branch-line coupler with low phase shift for WLANs," Analog Integrated Circuits and Signal Processing, vol. 98, no. 2, pp. 377-383, 2019.

[23] S. Lee and Y. Lee, "Wideband Branch-Line Couplers With Single-Section Arbitrary Coupling Levels," in IEEE Microwave and Wireless Components Letters, vol. 22, no. 1, pp. 19-21, 2012.

[24] J.-C. L. Kyo-Soon Choi, Ki-Cheol Yoon, Jae-Yeong Lee, Choul-Ki Lee, Seong-Cheol Kim, Ki-Byoung Kim, "Compact Branch-Line Coupler with Harmonics Suppression Using Meander T-Shaped Line," Microwave and Optical Technology Letters, vol. 56, no. 6, pp. 1382-1384, 2014.

[25] S. M. Hosseini and A. Rezaei, "Design Of A Branch-Line Microstrip Coupler Using Spirals And Step Impedance Cells For WIMAX Applications," Aro-The Scientific Journal of Koya University, vol. 8, no. 1, p. 1, 2020. 